\title{
Erratum to: Challenges and contributions of crop production in agro-pastoral systems of Borana Plateau, Ethiopia
}

\author{
Abera Tilahun ${ }^{1 *}$, Beyene Teklu² and Dana $\mathrm{Hoag}^{3}$
}

\section{Erratum}

\begin{abstract}
This erratum expands on the original article by Tilahun et al. (2017) published on 16 February 2017, and seeks to correct any oversights in the original article. Only the 'edited' paragraphs are available in this Erratum, the full original article can be accessed via: DOI 10.1186/ s13570-016-0074-9.
\end{abstract}

\section{Introduction}

In the introduction the relation between crop production and pastoralism is stated, the detailed introduction is as followed:

Followed these changes, pastoralists seek additional ways to earn a living as they watch historical pastoralist traditions fade over time (Fratkin, 2001). Thereby, livestock holding per household; income from livestock; livestock species composition has declined and also the gap between rich and the poor is widening (Teklu et al., 2015: Factors constraining livestock mobility and their implications on rangelands and livelihood of Borana pastoralists, Forthcoming). Crop production is one of the sources of income diversification available to pastoralists, and ironically one of the most important competitors to the pastoralist way of life (Tache, B., 2000: Individualizing the Commons: Changing resource tenure among the Borana Oromo of southern Ethiopia, unpublished). Why? Mainly because the cultivation takes over the key grazing resources, thus in a more serious case can lead to conflict between herders and cultivators. Introduction and expansion of cropping activities in pastoral lands is ongoing in Ethiopia, particularly in the Borana Plateau (Tache, B., 2000: Individualizing the Commons: Changing resource tenure among the Borana Oromo of

\footnotetext{
*Correspondence: abt2003@gmail.com

'Department of Dryland forestry, Wondo Genet College of Forestry and

Natural Resource, Hawassa University, Hawassa, Ethiopia

Full list of author information is available at the end of the article
}

southern Ethiopia, unpublished; Oba, G. 1998: Assessment of indigenous range management knowledge of the Booran pastoralists of southern Ethiopia). At the policy level, this fact is also generally accepted and acknowledged as one of the strategies for income diversification of the pastoralists and the support for cropping is likely to continued (Mohammed, M., 2004: A comparative study of pastoralist parliamentary groups: Case study on the pastoral affairs standing committee of Ethiopia, unpublished).

In the original paper 2 objectives have been stated, but these should have been the following 3: (i) to identify major determinants of crop production in pastoralist households, (ii) to assess the contribution of crop production to the household economy of agro-pastoral communities, and. (iii) to identify the challenges.

\section{Study area}

Furthermore, in the following paragraph the rainfall data is expanded to show more recent rainfall data and to give clarification for the updated districts.

Average annual rainfall ranges between 350 and $900 \mathrm{~mm}$, with considerable spatial and temporal variability in quantities and distribution (Coppock 1994: in Homann et al., 2007). According to a new organizational structure in Oromia, the Borana Zone has been divided into two zones, the Borana and Gujji. The Borana Zone is the southern parts and has thirteen districts (woredas), namely Abaya, Arero, Bule Hora, Dhas, Dillo, Dirre, Duda Dawa, Gelana, Megala, Miyo, Moyale, Teltele, and Yabelo (Borana Zonal Administration, 2014.

In the following section the first paragraph of the 'Surveys and analysis methods' section is further detailed by adding information such as the selection criteria and the 'definition of pastoral and agro-pastoral groups'. Furthermore, detailed information has been added to indicate the socio-economic classes.The updated study map is also visible which no longer shows the PA's of "Harweyu" and "Medicho" as those PA's are not covered in the original article. 
Table 1 Wealth indicators of the agro-pastoralist community

\begin{tabular}{llll}
\hline Indicators & Rich & Medium & Poor \\
\hline Number of cattle & $>40$ & $10-40$ & $<10$ \\
Cultivated land (ha) & $>3$ & $1-3$ & $<1$ \\
Number of Goats and sheep's & $>30$ & $10-30$ & $>10$ \\
Number of camel & $>30$ & $3-30$ & $1-2$ \\
Area closure (ha) & $>2$ & $1-2$ & $<1$ \\
Rent house & $\checkmark$ & - & - \\
Need support & - & - & $\checkmark$ \\
\hline
\end{tabular}

A multistage sampling technique was employed to select sample households and collect the necessary data for the study (Table 1). In the first stage, two representative districts, Yabello and Dire (Fig. 1) were selected; covering over $15 \%$ of the Borana Zone. The selection of the districts was made on the account that the two districts represent agro-pastoral communities where crop farming is widely practiced. In the second stage, peasant associations (PAs) of each district were systematically categorized under agro-pastoral and pastoral on the basis of livelihood system obtained from a reconnaissance survey and discussions with district level pastoral development government offices. In the third stage, from the agro-pastoral group a total of four peasant associations (4PAs), two from each district were selected randomly and then, households in each selected PAs were categorized into three socio-economic classes i.e. rich, medium and poor (Table 1). With a sample of about 5\% of the total households in the 4PAs (total households is estimated to be (1184), the total sample size was 60 households. Accordingly, 15 households were chosen from each of the four selected PAs; the 15 sample households were distributed by the three socio-economic classes in each $P A$ as shown in (Table 2). Finally, a random sampling method was used to select the sample households from each socio-economic class in each of the four PAs for the detailed household survey in order to balance the sample across our regional and social strata in proportions reflective of the community.

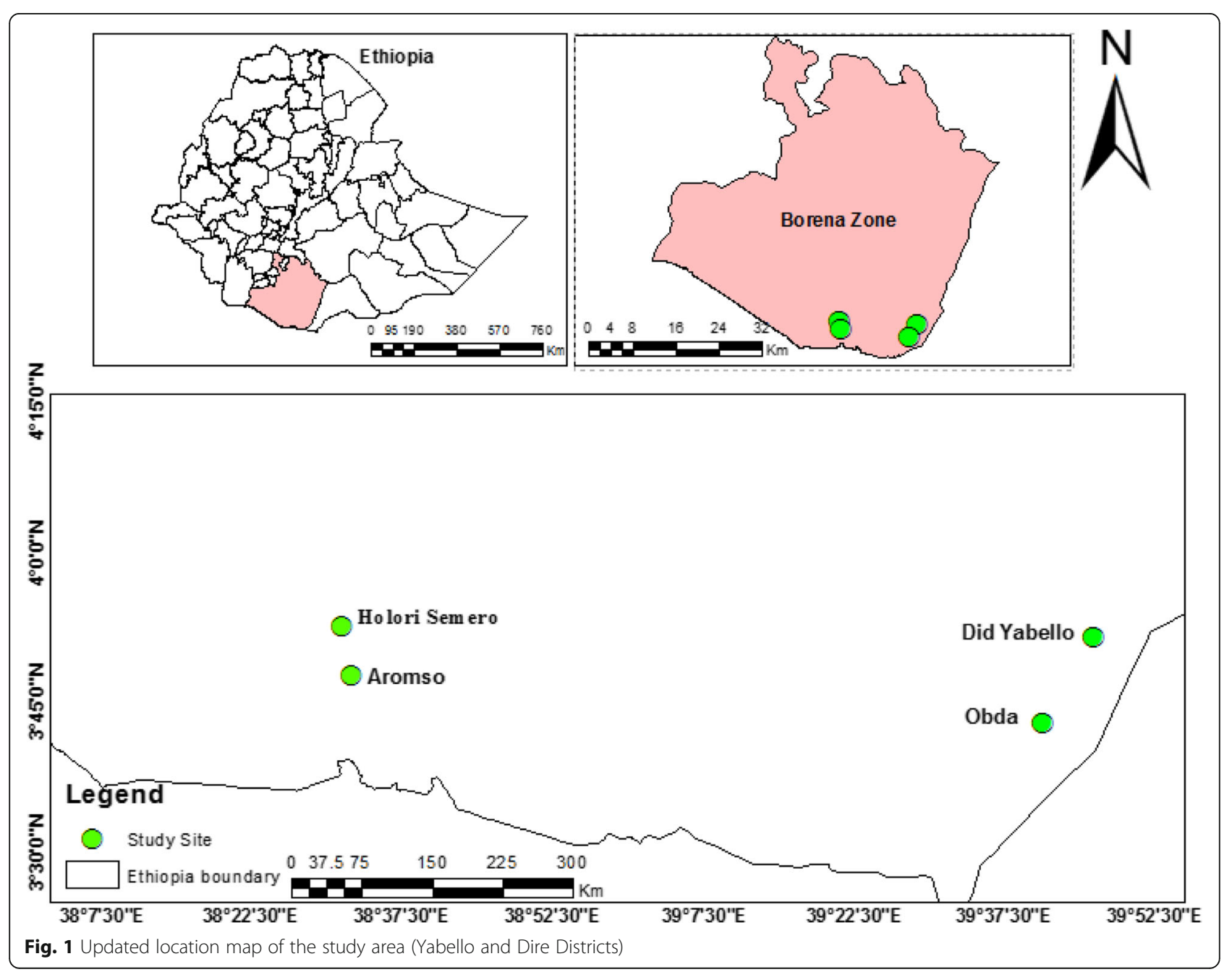




\section{Author details}

'Department of Dryland forestry, Wondo Genet College of Forestry and Natural Resource, Hawassa University, Hawassa, Ethiopia. ${ }^{2}$ Department of Animal and Range Sciences, Wondo Genet College of Forestry and Natural Resource, Hawassa University, Hawassa, Ethiopia. ${ }^{3}$ Department of Agricultural and Resource Economics, Colorado State University, Fort Collins, CO, USA.

Published online: 29 May 2017

\section{References}

Coppock, DL. 1994. The Borana Plateau of Southern Ethiopia: Synthesis of Pastoral Research, Development, and Change, 1980-91 (Systems Study No. 5). International Livestock Center for Africa, Addis Ababa, Ethiopia. 370.

Fratkin, E. 2001. East African pastoralism in transition: Maasai, Borana and Rendille cases. African Studies Review 44: 1-25.

Tilahun, A, et al. 2017. Challenges and contributions of crop production in agropastoral systems of Borana Plateau, Ethiopia. Pastoralism 7: 2. doi:10.1186/ s13570-016-0074-9. 